Meta

Journal des traducteurs

Translators' Journal

\title{
Interactive Translation vs. Pre-Translation in TMs: A Pilot Study
}

\section{Julian M. S. Wallis}

Volume 53, numéro 3, septembre 2008

URI : https://id.erudit.org/iderudit/019243ar

DOI : https://doi.org/10.7202/019243ar

Aller au sommaire du numéro

Éditeur(s)

Les Presses de l'Université de Montréal

ISSN

0026-0452 (imprimé)

1492-1421 (numérique)

Découvrir la revue

Citer cet article

Wallis, J. M. S. (2008). Interactive Translation vs. Pre-Translation in TMs: A Pilot Study. Meta, 53(3), 623-629. https://doi.org/10.7202/019243ar

\section{Résumé de l'article}

Les mémoires de traduction (MT) sont présentement l'un des outils de traduction les plus convoités sur le marché. Aujourd'hui, les clients recherchent la productivité et la qualité, sans que cela affecte de façon négative leurs revenus. Deux méthodes s'offrent à l'utilisateur lors de la traduction avec une MT : la traduction interactive et la pré-traduction. Jusqu'à maintenant, on ignore si le choix entre la traduction interactive et la pré-traduction produit un effet sur la productivité, la qualité et la satisfaction du traducteur. Le présent article se propose d'analyser les deux méthodes de traduction avec MT à l'aide d'une méthodologie comparative. 


\title{
Interactive Translation vs. Pre-Translation in TMs: A Pilot Study
}

\author{
JULIAN M. S. WALLIS \\ University of Ottawa, Ottawa, Canada \\ jwall035@uottawa.ca
}

\begin{abstract}
RÉSUMÉ
Les mémoires de traduction (MT) sont présentement l'un des outils de traduction les plus convoités sur le marché. Aujourd'hui, les clients recherchent la productivité et la qualité, sans que cela affecte de façon négative leurs revenus. Deux méthodes s'offrent à l'utilisateur lors de la traduction avec une MT: la traduction interactive et la pré-traduction. Jusqu'à maintenant, on ignore si le choix entre la traduction interactive et la pré-traduction produit un effet sur la productivité, la qualité et la satisfaction du traducteur. Le présent article se propose d'analyser les deux méthodes de traduction avec MT à l'aide d'une méthodologie comparative.
\end{abstract}

\begin{abstract}
Translation clients today are looking for high productivity and quality, but are looking for these at reduced costs. Translation Memory (TM) systems are currently among the most popular translation tools on the market and are intended to help translators produce more translations in a short time period while maintaining high quality and consistency in their work. There are two ways of working with a TM system: interactive mode and pre-translation mode. However, there have been no studies to date which attempt to determine whether one mode is superior to the other. This paper describes a pilot study which investigates which of the two produces better results in terms of productivity, quality and translator satisfaction.
\end{abstract}

\section{MOTS-CLÉS/KEYWORDS}

Translation Memory (TM), interactive translation, pre-translation, productivity, quality

\section{Introduction}

Translation technology has been increasing in popularity in recent years, and one of the most popular tools on the market is the Translation Memory (TM) system, which allows translators to "recycle" parts of previous translations. However, since it is only relatively recently that translators have begun using these tools on a wide scale, there has not yet been a substantial amount of research into the impact that they have on translators or their work. This paper describes a methodology developed to compare two different ways of working with a TM system - interactive mode and pre-translation mode - in order to determine which seems to be the most beneficial with regard to increasing translation productivity, translation quality, and translator satisfaction. The paper is divided into 4 main parts. Section 1 explains some of the challenges associated with the translation market and outlining the impact of TMs on the market. Section 2 introduces the two methods of working with a TM. Section 3 describes the pilot study. Section 4 offers some concluding remarks. 


\subsection{Challenges in the Translation Market}

The translation industry is currently facing a number of challenges, including a growing demand for translation coupled with shorter deadlines and a shrinking workforce (Charron 2005). Today, the volume of translation is rapidly increasing due to globalization, and pressure on translators to produce high-quality translations in shorter times is also increasing since many companies are looking to ship all language versions of a product simultaneously. However, despite the fact that the volume of translation is increasing, there is a current shortage of trained translators, and relatively few graduates of translation programs are entering the industry (CTISC 1999).

As a result, more translators are turning to technology to help increase productivity, while still maintaining a high quality. As discussed by researchers (e.g. L'Homme 1999; Esselink 2000; Austermühl 2001; Bowker 2002), many tools and resources are available to translators, such as corpus-analysis tools, terminology managers and machine translation; however, the most popular tools today are TMs, which contain an aligned database of previous translations that can be searched to find solutions for new translations.

\subsection{Impact of Technology}

TMs are proving to be a very valuable translation commodity, and both translators and their clients would like to claim ownership over the TM database. However, as pointed out by Topping (2000: 59), from a legal perspective, neither party appears to have clear-cut ownership rights, so the matter is being hotly debated. Many translators believe that since they are putting their time and effort into building up the TM, they should own it because it is their intellectual property.

Meanwhile, the client's perspective is presented by Yunker (2003: 221), who states "once you translate a sentence, you shouldn't have to pay for it to be translated again." In fact, many TM systems contain a repetition analysis module that clients can use to compare new source texts against the TM database to determine approximately how much of the text can be recycled. As a result, clients are beginning to demand discounts for any text translated with the aid of a TM.

TMs can clearly help translators increase their productivity, and if discounts are given for matches retrieved from the TM, costs can be reduced. Because clients can get their translations more quickly and cheaply if a translator uses a TM, some clients are insisting that this technology be used. However, this raises some additional issues.

Firstly, TM systems are relatively expensive, and not all translators own one. Secondly, there are a wide variety of TM tools on the market, and it is not yet easy to transfer data between all these systems. ${ }^{1}$ Therefore, even if a translator does have a TM, it may not be the same TM that the client uses. Thus, in a market that is already experiencing a shortage of translation professionals, the pool of translators available to clients who insist on the use of a TM - not to mention a particular TM - is even smaller.

One solution is for the client to give a translator access to the client's TM for the duration of the project. Some clients do choose this; however, an increasing number are hesitant to give translators direct access to their TMs due to proprietary issues. The client does not want the translator using their TM do to work for another client. 
Therefore, another solution that is beginning to appear is one that makes use of a strategy called pre-translation. In a TM system, pre-translation is a function that compares the new source text against the contents of the TM database and automatically inserts any target-language matches directly into the source text. The result is a partially translated or hybrid text containing some fragments in the target language, and others that remain in the source language. The client can then give the hybrid text to the translator whose job is to translate the remaining parts of the text for which no matches could be found. In principle then, the client can provide the translator with material from the TM without giving her/him direct access to it. However, an important question that remains is how pre-translation compares to working interactively with a TM, particularly as regards productivity, quality and translator satisfaction.

\section{Overview of TM Systems}

Detailed descriptions of how TM systems operate can be found in the literature (e.g. L'Homme 1999; Bowker 2002), so only a brief description will be given here. Basically, TMs process texts in small chunks known as segments, which usually correspond to sentences or sentence-like structures. When texts are added to a TM, the tool automatically divides them into segments, and then aligns the corresponding segments from source and target texts to produce translation units (TUs), which are stored in the database for future reuse.

\subsection{Interactive Translation}

The most common way of working with a TM is in interactive mode where a translator opens the new text to be translated within the TM environment and proceeds to translate in a linear fashion (i.e., sentence by sentence). The translator can consult the TM database or associated term base, accept or refuse proposed matches and view the results of each segment to be translated.

In interactive mode, when a translator opens the new source text, the TM system first divides this text into segments. The TM then takes the first segment of this new text and compares it against all the segments stored in the database. This comparison is done strictly on the basis of "character-string similarity" (Somers 2003: 38), meaning that the spelling, punctuation and all other parts of the segments are taken into account when the TM system tries to find matches.

\subsection{Matches}

When the system finds a match, it retrieves the matching TU from the database and presents it to the translator, who can accept, modify, or reject it. There are a number of possible types of matches.

- Exact match: a segment that is identical in every way to one already stored in the database.

- Fuzzy match: a segment that is similar to one stored in the TM database. ${ }^{2}$

- Sub-segment match: a chunk of a segment that is similar to a chunk of a segment stored in the TM database. 
- Term match: a term found in the source text that matches one found in the term base associated with the TM system.

\subsection{Pre-translation}

Most TM systems also permit pre-translation, which Heyn (1998: 129) describes as the process of partially translating a text by having a TM system automatically replace elements in the source text with target language equivalents taken from the TM database or term base. As noted above, pre-translation is gaining favour among clients who do not wish translators to access their TMs directly.

\section{Pilot Study}

A pilot study was carried out and three hypotheses were formulated and then tested in an experiment. Clearly, the scale of the experiment was too small to produce definitive results; however, it did generate some interesting preliminary findings that suggest it could be worth scaling up this investigation.

\subsection{Hypotheses}

- Productivity: Translators working with pre-translated texts will have a lower productivity than translators working interactively with TMs because the former will need to spend more time trying to decipher the hybrid text and finding target language formulations that fit in with those parts of the text that have already been translated.

- Quality: Translators working with pre-translations will produce lower-quality translations than translators working in interactive mode because the former are obliged to work with texts that have been partially translated using a variety of different styles, and they do not have access to all the information contained in the TM database.

- Translator satisfaction: Translators working with pre-translations will have lower job satisfaction than translators working interactively with TMs because the former are obliged to adapt their style to that which is already contained in the pre-translated text, which means they will have less control over the creation of a holistic text.

\subsection{Experiment}

To test the validity of these hypotheses, an experiment was conducted. It included a relatively homogeneous group of 4 students from the MA in Translation program at the University of Ottawa who acted as French-to English translators, and two professors who acted as evaluators. The subject field was UV radiation and the ozone layer. The Fusion Translate ${ }^{\mathrm{Tm}}$ system was used to create a TM database of approximately 2700 TUs. Two 350-word source texts from the same subject field were chosen to be translated for the experiment.

For the experiment, each translator translated 2 texts: one in interactive mode and one in pre-translation mode. To ensure that it was not simply the source text (ST) that was conducive to one or the other method of translation, translators A and 
B used ST1 in pre-translation mode and ST2 in interactive mode, and the other two did the opposite. The translators recorded the time required to do each translation. They also filled out a questionnaire about which method proved more satisfactory and why. The 8 translations were then assessed by the evaluators according to a set of pre-established evaluation guidelines.

\subsection{Data analysis}

\subsubsection{Productivity}

Table 1 lists the time required for each translation.

TABLE 1

\section{Productivity of translators}

\begin{tabular}{|l|l|l|}
\hline Translators & $\begin{array}{l}\text { Interactive } \\
\text { Translation }\end{array}$ & Pre-Translation \\
\hline Translator $A$ & $49 \min ($ text 2$)$ & $49 \min ($ text 1$)$ \\
\hline Translator $B$ & $64 \min ($ text 2$)$ & $55 \min ($ text 1$)$ \\
\hline Translator $C$ & $51 \min ($ text 1$)$ & $60 \min ($ text 2$)$ \\
\hline Translator $D$ & $46 \min ($ text 1$)$ & $46 \min ($ text 2$)$ \\
\hline
\end{tabular}

Since two of the translators recorded the same time for their pre-translation and interactive translation tasks, and since one of the others showed improvement when working in interactive mode and the other when working in pre-translation mode, the tentative conclusion based on this data is that the translation method has no significant impact on the productivity of a translator.

\subsubsection{Quality}

The evaluators assigned a score to each translation, which made it possible to compare the results and determine, for each translator, which method resulted in a higher quality text. A summary of the results is contained in Table 2.

TABLE 2

Relative quality of translations

\begin{tabular}{|c|c|c|c|}
\hline & & $\begin{array}{l}\text { Method producing } \\
\text { higher quality }\end{array}$ & Margin of improvement \\
\hline \multirow{2}{*}{ Translator A } & Evaluator 1 & No difference & No difference \\
\hline & Evaluator 2 & interactive & Insignificant (4\%) \\
\hline \multirow{2}{*}{ Translator $B$} & Evaluator 1 & interactive & Insignificant $(7 \%)$ \\
\hline & Evaluator 2 & interactive & Significant (52\%) \\
\hline \multirow{2}{*}{ Translator $C$} & Evaluator 1 & pre-translation & Insignificant (3\%) \\
\hline & Evaluator 2 & pre-translation & Significant $(27 \%)$ \\
\hline \multirow{2}{*}{ Translator D } & Evaluator 1 & interactive & Insignificant (7\%) \\
\hline & Evaluator 2 & interactive & Significant $(25 \%)$ \\
\hline
\end{tabular}

The data provide only weak support for the hypothesis that interactive mode produces higher quality texts. Slightly more than half of the time ( 5 times out of 8 ) the evaluators 
judged the texts produced using interactive mode to be of higher quality, though on 3 out of the 5 occasions, they were rated as being only slighter better.

\subsubsection{Translator satisfaction}

Based on the questionnaire responses, the translators prefer working interactively, which supports the hypothesis. Two of the four translators were more satisfied with the text that resulted from interactive mode whereas the other two were equally satisfied with the results of both methods. Moreover, all preferred working with the TM to working without it and agreed that if asked by a client to work with a TM they would choose interactive mode over pre-translation mode.

\section{Concluding remarks}

The results of this small experiment show that while productivity seems comparable across the two methods, the quality of the texts appears to be slightly higher when using interactive mode, and the job satisfaction is considerably higher in this mode also. Clients should keep this in mind when seeking translations. As noted in section 1.2 , some clients choose pre-translation because they are afraid of giving translators access to their TM databases, but they may not realize that they could be getting lower quality texts as a result. Moreover, with so much translation work available, and relatively few translators to do it, translators are in the happy position of being able to select which jobs they accept, and since it appears that they do not like working with pre-translations, clients who do not permit interactive translation may have trouble finding translators to work for them.

\section{NOTES}

1. The Translation Memory eXchange (TMX) standard will help to alleviate this problem, but it has not yet been implemented in all TM systems.

2. A user can adjust the minimum match value according to the degree of fuzziness desired (e.g. $70 \%$, $80 \%$, etc.).

\section{REFERENCES}

AustermüHL, F. (2001): Electronic Tools for Translators, Manchester, St. Jerome.

Bowker, L. (2002): Computer-Aided Translation Technology: A Practical Introduction, Ottawa, University of Ottawa Press.

Canadian Translation Industry Sectoral Committee (1999): Survey of the Canadian Translation Industry: Human Resources and Export Development Strategy, <www.uottawa.ca/associations/csict/princi-e.htm>.

Charron, M. (2005): "Plus vite, encore plus vite: la traduction à l'heure de la mondialisation," Translation Studies in the New Millennium 3, pp. 15-27.

Esselink, B. (2000): A Practical Guide to Localization, Amsterdam/Philadelphia, John Benjamins.

Heyn, M. (1998): “Translation Memories: Insight and Prospects," Bowker, L., Cronin, M., Kenny, D. and J. Pearson (eds.) Unity in Diversity? Current Trends in Translation Studies, Manchester, St. Jerome, pp. 123-36.

L’Hомме, M.-C (1999): Initiation à la traductique, Brossard, Québec, Linguatech.

Somers, H (2003): “Translation Memory Systems," in Somers, H. (ed.) Computers and Translation: A Translator's Guide, Amsterdam/Philadelphia, John Benjamins, pp. 31-47. 
Topping, S (2000): "Sharing Translation Database Information: Considerations for developing an ethical and viable exchange of data," Multilingual Computing and Technology 11-5, pp. 59-61.

Yunker, J (2003): Beyond Borders: Web globalization strategies, Indianapolis, New Riders Publishing. 